\title{
Endosomal Cholesterol in Viral Infections - A Common Denominator?
}

\author{
Mirco Glitscher and Eberhard Hildt* \\ Department of Virology, Paul-Ehrlich-Institute, Langen, Germany
}

Cholesterol has gained tremendous attention as an essential lipid in the life cycle of virtually all viruses. These seem to have developed manifold strategies to modulate the cholesterol metabolism to the side of lipid uptake and de novo synthesis. In turn, affecting the cholesterol homeostasis has emerged as novel broad-spectrum antiviral strategy. On the other hand, the innate immune system is similarly regulated by the lipid and stimulated by its derivatives. This certainly requires attention in the design of antiviral strategies aiming

OPEN ACCESS

Edited by: Hester Gertruida O'Neill, University of the Free State,

South Africa

Reviewed by:

Cathleen Carlin,

Case Western Reserve University, United States

Covadonga Alonso,

Instituto Nacional de Investigación y Tecnología Agroalimentaria (INIA),

Spain

${ }^{*}$ Correspondence: Eberhard Hildt eberhard.hildt@pei.de

Specialty section: This article was submitted to Lipid and Fatty Acid Research, a section of the journal

Frontiers in Physiology

Received: 30 July 2021 Accepted: 22 October 2021 Published: 11 November 2021

Citation:

Glitscher M and Hildt E (2021) Endosomal Cholesterol in Viral Infections - A Common Denominator?

Front. Physiol. 12:750544. doi: 10.3389/fphys.2021.750544 to decrease cellular cholesterol, as evidence accumulates that withdrawal of cholesterol hampers innate immunity. Secondly, there are exceptions to the rule of the abovementioned virus-induced metabolic shift toward cholesterol anabolism. It therefore is of interest to dissect underlying regulatory mechanisms, which we aimed for in this minireview. We further collected evidence for intracellular cholesterol concentrations being less important in viral life cycles as compared to the spatial distribution of the lipid. Various routes of cholesterol trafficking were found to be hijacked in viral infections with respect to organelle-endosome contact sites mediating cholesterol shuttling. Thus, re-distribution of cellular cholesterol in the context of viral infections requires more attention in ongoing research. As a final aim, a pan-antiviral treatment could be found just within the transport and re-adjustment of local cholesterol concentrations. Thus, we aimed to emphasize the importance of the regulatory roles the endosomal system fulfils herein and hope to stimulate research in this field.

Keywords: cholesterol, trafficking, viruses, endosomes, antivirals, host-factors

\section{INTRODUCTION}

Viral infections certainly present one of the biggest concerns of our society leading to a tremendous number of deaths worldwide. In the fight against virus-induced diseases, several antiviral medications have emerged and were approved (de Clercq and Li, 2016). However, the majority of these compounds are either specific for a class of viruses, induce heavy adverse effects, or lead to viral escape mutations (Sleijfer et al., 2005; de Clercq and Li, 2016; Domingo et al., 2019). Thus, a search for a tolerable and pan-antiviral therapy has emerged. A strong focus now is set on affecting the host's cholesterol metabolic network (Lembo et al., 2016; Yuan et al., 2019; Gorabi et al., 2020). For reasons explained in this article, a variety of studies focus on the reduction of cellular cholesterol. Recent evidence 
implies that this may not only present a strategy against enveloped viruses. Various non-enveloped viruses make use of the exosomal pathway or autophagy for their release, thus being dependent on membranous processes just as well (Jiang et al., 2011; Zhang et al., 2021). Consequently, the majority of studies follow the assumption that a certain net amount of cellular cholesterol per se is required in viral life cycles. While this may be true for various viruses, some examples demonstrated that cholesterol depletion actually behaves provirally (Jung et al., 2012; Blanchet et al., 2016; Glitscher et al., 2021). While altering the cholesterol homeostasis in the host appears as a promising pan-antiviral strategy, ambiguous behaviors hinder the progress in finding exactly this. A problem therefore addressed by us is that it may not come down to how much cholesterol resides within a cell. Rather, we believe, it is important where and how the cholesterol pool is distributed within a cell. We therefore try to give an overview of the current knowledge, gaps in knowledge, and possible prospects in how cholesterol trafficking mediated by endosomes may be useful to this overall aim.

\section{MODULATION OF CELLULAR CHOLESTEROL CONTENT IN VIRAL INFECTIONS}

\section{Cholesterol Synthesis and Uptake}

A wide range of viruses induces cholesterol anabolism, suggesting a general shift toward cholesterol uptake and de novo synthesis in infected cells. Central processes hereof are transcriptionally regulated by sterol-regulatory element binding proteins (SREBPs). These ER-resident proteins are maintained in a complex together with insulin-induced gene 1 (INSIG1), SREBP cleaving-activating protein (SCAP), and sterols (Yang et al., 2002). Upon depletion of the latter, INSIG1 dissociates and the SREBP-SCAP complex traffics to the Golgi apparatus (Sun et al., 2007). Subsequent cleavage releases the transcription factor (TF) domain to be shuttled into the nucleus (Wang et al., 1994). Herein, SREBPs drive the expression of a variety of genes being responsible for increasing cellular cholesterol. Two major key players are the 3-hydroxy-3-methyl-glutaryl-coenzyme A reductase (HMGCR), catalyzing the rate-limiting step in cholesterol synthesis (Geelen et al., 1986), and the low-density lipoprotein (LDL) receptor (Yokoyama et al., 1993), binding the major cholesterol-carrying lipoprotein. This point of control is hijacked by a variety of viruses. Human cytomegalovirus (HCMV), hepatitis B virus (HBV) or hepatitis C virus (HCV) activate SREBP activity through enhancing its proteolytic cleavage (Waris et al., 2007; Yu et al., 2012; Qiao et al., 2013). Additionally, a correlation between early viral infections and a rise in LDL uptake and cholesterol biosynthesis were observed for Dengue virus (DENV) or West Nile virus (WNV; Mackenzie et al., 2007; Soto-Acosta et al., 2013). Also for non-enveloped viruses, such as the Coxsackievirus B3 (CVB3), an activation of SREBPs was observed (Wang et al., 2018) and may be similarly important for viruses making use of the exosomal pathway, such as
Enterovirus 71 (EV71), human Norovirus (HuNoV), Rotaviruses, or encephalomyocarditis virus (EMCV; Owusu et al., 2021). Following these findings, cholesterol removal from infected cells could correlate with benefits for a viral infection.

\section{Cholesterol Export}

On the other hand, cholesterol depleting processes need to be taken into account, which are majorly regulated via two different nuclear receptors acting as TFs: (i) liver $\mathrm{X}$ receptors (LXR) and (ii) farnesoid X receptors (FXR). The former is activated by sterols and oxysterols (Janowski et al., 1996) and primes expression of the cholesterol export program. Among various targets, ATP-binding cassette transporter A1 (ABCA1) is induced, which shuttles cholesterol into the extracellular space. This process is aided by cholesterol transport from endolysosomes to the plasma membrane (PM) via, for example, the Niemann-Pick C1 protein (NPC1; Boadu and Francis, 2006; Boadu et al., 2012). As a result, high-density lipoprotein (HDL) is formed with the help of ATP-binding cassette transporter G1 (ABCG1) and apolipoprotein A1 (ApoA1) leading to cholesterol export from cells (Gelissen et al., 2006; Zhao et al., 2012). At this level, viruses, such as human immunodeficiency virus (HIV), HCV, and HCMV, have been demonstrated to impair ABCA1 activity via reduced expression (Mujawar et al., 2006; Sanchez and Dong, 2010; Shirasaki et al., 2013). Further, both HBV and severe acute respiratory syndrome coronavirus 2 (SARS-CoV-2) seem to decrease ApoA1 levels (Wang et al., 2016; Yang et al., 2020), thereby also reducing HDL-related cholesterol export. Effectively, these regulations would match to an increase in cholesterol anabolism, thus increasing the lipid in an infected cell.

\section{Cholesterol Derivatization}

Apart from cholesterol export, derivatization into bile acids (BAs) is a way to rid a cell from the lipid specifically in liver tissue. The expression of both rate-limiting enzymes, namely, the ER-resident cholesterol 7 alpha-hydroxylase (CYP7A1) or the mitochondrial sterol 27-hydroxylase (CYP27A1), is induced by LXR (Gupta et al., 2002; Szanto et al., 2004). Once primary bile acids are synthesized, FXR represses these anabolic enzymes (Forman et al., 1995; Chiang, 2015) and enhances BA export via ATP-binding cassette transporter B11 (ABCB11; Ananthanarayanan et al., 2001; Deng et al., 2006) or the organic solute transporter subunit alpha and beta $(\mathrm{OST} \alpha / \beta$; Ballatori et al., 2005; Landrier et al., 2006). Both LXR and FXR activity is fine-tuned by co-factors represented by the nuclear receptors retinoic X receptors (RXR) or peroxisome proliferator-activated receptors (PPARs; Seol et al., 1995; Kassam et al., 2003; Pineda Torra et al., 2003). As a liver-specific process, BA synthesis and export are mainly affected by enteric and hepatotropic viruses. For instance, an activation of FXR is related to proviral effects for HBV, HCV, or HuNoV (Scholtes et al., 2008; Mouzannar et al., 2019; Murakami et al., 2020). In turn, the activation of FXR would result in an impaired BA synthesis and render cholesterol levels to rise. This again supports the claim of viruses elevating cellular cholesterol. 


\section{Cholesterol Storage}

A third way of removing cholesterol from a cell is via esterification and subsequent intracellular storage. This catalytic process is mediated by the ER-resident acyl-coenzyme A:cholesterol acyltransferase (ACAT), which is activated by cholesterol (Cheng et al., 1995). As a consequence, cholesterol esters are stored in lipid droplets (LDs) rendering cholesterol to be biologically inactive. The morphogenesis and depletion of LDs are strictly coordinated (Olzmann and Carvalho, 2019) and similarly are made use of by different viruses. The predominant example is HCV, which strongly depends on these structures for virion morphogenesis (Barba et al., 1997; Boulant et al., 2007). However, also a variety of other viruses induce the formation of LDs among which are DENV, Zika virus (ZIKV), Herpes simplex virus 1 (HSV-1), Influenza A virus (IAV; Samsa et al., 2009; Monson et al., 2021), and Adenovirus RID $\alpha$ (Cianciola et al., 2013). Consequently, viruses requiring LDs present a group contradicting with a general increase in biologically available net cholesterol content in cells. While they do require cholesterol synthesis and uptake, it would then be stored rather than being available within membranes.

\section{INNATE IMMUNITY}

\section{Pathogen Recognition Receptors}

Just as viral life cycles, the innate immune response against the pathogens is regulated by cholesterol, which is initiated by pathogen-associated molecular patterns (PAMPs) being sensed by pathogen recognition receptors (PRRs). Here, toll-like receptors (TLRs) represent PRRs being either present on the PM or within endosomes majorly recognizing nucleic acids (Latz et al., 2004; Nishiya et al., 2005; Husebye et al., 2006; Johnsen et al., 2006; Nilsen et al., 2008; Ishii et al., 2014; Lester and Li, 2014). They share a close relationship with ABCA1-dependent cholesterol removal, which interferes with downstream cascades and vice versa (Zhu et al., 2008, 2010; Guo et al., 2015; Li et al., 2018; Ding et al., 2020). Similarly, TLR activity seems to decline upon application of statins, inhibitors of cholesterol synthesis (Mullen et al., 2015; Bahrami et al., 2018; Venardos et al., 2018). A second class of PRRs is represented by retinoic acid-inducible gene-I-like receptors (RIG-I-like receptors or RLRs). An activation by PAMPs subsequently triggers oligomerization of mitochondrial antiviral signaling protein (MAVS) on the outer mitochondrial membrane, which passes signaling on to the production of IFNs (Zamorano Cuervo et al., 2018; Rehwinkel and Gack, 2020). While little is known about cholesterol controlling the related pathway, RIG-I signaling seems to involve the oxysterol 25-hydroxycholesterol (Wang et al., 2012). Further, the predominant localization of MAVS at ER-mitochondrion contact sites with high cholesterol content (Horner et al., 2011) implies that its oligomerization could be regulated by local cholesterol concentrations. Further elucidation is required to understand these relationships in detail.

\section{Interferon Response}

Downstream of PRRs, respective signaling cascades elicit the production of cytokines among which are IFNs. These result in myriads of regulatory alterations in targeted cells, ultimately mediating host-defense mechanisms. An interesting link to cholesterol can be drawn by IFNs inducing a key enzyme in the buildup of cholesterol-derivatives, namely, cholesterol 25-hydroxylase $(\mathrm{CH} 25 \mathrm{H})$. The latter produces an oxysterol, 25-hydroxycholesterol, which has been described as broadly antiviral via diverse mechanisms (Zhao et al., 2020) against, for example, HSV, IAV, SARS-CoV-2, and members of the Flaviviridae or Filoviridae families (Liu et al., 2013; Chen et al., 2014; Wang et al., 2020). In general, oxysterols also serve important functions in regulating the IFN response and production of the cytokines. Oxysterol production is inducible by IFNs (Marquis et al., 2011; Blanc et al., 2013).These in turn activate LXR (Lehmann et al., 1997), which boosts production of IFN $\gamma$ (Wang Q. et al., 2014). This could serve the purpose of inducing antiviral activity, as LXR has been described to induce viral restriction if induced pharmacologically (Sheng et al., 2016; Lange et al., 2018, 2019; Mlera et al., 2021). Further, oxysterols themselves exert similar antiviral effects against manifold viruses (Civra et al., 2014, 2018; Anggakusuma et al., 2015; Willard et al., 2018; Marcello et al., 2020; Zu et al., 2020; Glitscher et al., 2021). Opposing to this, however, stand studies describing a negative feedback loop of IFN $\gamma$ reducing LXR and FXR activity (Renga et al., 2009; Pascual-García et al., 2013). Effectively, this would increase cellular cholesterol levels, as observed in further studies (Hao et al., 2013; Robertson and Ghazal, 2016; Kühnl et al., 2018). More research is required elucidating the mechanism regulating these opposing effects especially with respect to the change in net cholesterol, which previously was assumed to be essential to viruses.

\section{Inflammasome}

The inflammasome is a multiprotein complex and a prime mediator for inflammatory processes and pyroptosis. Upon establishment of cellular stress or exposure to pathogens and subsequent PAMP-sensing, different subunit combinations of the complex assemble. In its core, homo-oligomers of either pro-caspase 1 or 8 are found. These may then be followed by an accessory proteins connecting the inner core with the outer subunits mediating specificity toward the activating agent. These outer subunits are represented by NLR family CARD domaincontaining protein 4 (NLRC4), NLR family pyrin domaincontaining 3, 6, or 7 (NLRP3/6/7), interferon-inducible protein AIM2 (AIM2), gamma-interferon-inducible protein Ifi-16 (IFI16), or pro-caspases 11,4 , or 5 . As a result upon activation, the inner caspases proteolytically activate interleukins $1 \beta$ and 18 (IL1 $\beta / 18)$, mediating inflammation, or gasdermin $\mathrm{D}$, initiating pyroptosis (Zheng et al., 2020). Interestingly, the inflammasome presents an additional step regulated by cholesterol. Efficient activation of the complex machinery by NLRP3 hereby is reliant on cholesterol shuttling to the ER (de La Roche et al., 2018) and enhanced by cholesterol accumulation (Le Bras, 2018). In line with this, cholesterol efflux reduces the activity of the 
inflammasome (Westerterp et al., 2018). Concordantly, the activation of SREBP-mediated cholesterol synthesis seems to be enhanced by the latter (Im et al., 2011; Li et al., 2013; Guo et al., 2018) and sets LD-mediated, virus-induced inflammatory responses into a fitting context (Negash et al., 2013; Dias et al., 2020).

\section{CHOLESTEROL IN THE ENDOSOMAL SYSTEM}

As implied by mechanisms summarized above and in Figure 1, cholesterol affects a variety of steps in the cellular and thereby viral life cycle. Although almost all viruses have an impact on cholesterol metabolism and cholesterol import, there are profound differences with respect to the effect of cholesterol on the viral life cycle. In light of this, it appears rational to affect a central factor involved in cholesterol uptake and intracellular transport as a target for antiviral therapies. One such factor is represented by the endosomal system, which primarily is described as the transporting machinery from components of the extracellular space to intracellular organelles. Primed by endocytosis, early endosomes (EEs) are formed close to the PM. These can either differentiate into recycling endosomes (REs) flowing into the endosomal recycling compartment (ERC), from where cargo is shuttled back to the PM (Xie et al., 2016), or they can mature into late endosomes (LEs;
Stoorvogel et al., 1991). On the way from EEs to LEs, the endosomal system can be fed via two further routes: (i) vesicles originating from the trans-Golgi network (TGN; Burd and Cullen, 2014; Nagano et al., 2019), aiding in endosomal maturation, and (ii) autophagosomes (Gordon and Seglen, 1988; Ganesan and Cai, 2021), mediating cargo release (Claude-Taupin et al., 2017) or degradation. Further, cargo loading of the endosomal system is mediated by a distinct subset of late endosomes, namely, multivesicular bodies (MVBs). Sorting herein is mediated by the endosomal complexes required for transport (ESCRT) machinery (Frankel and Audhya, 2018), which incorporates molecules into intraluminal vesicles, hence the name MVBs. Cargo, being either protein, nucleic acids or lipids, is then targeted for release via exosomes (Hessvik and Llorente, 2018) or degradation via fusion with lysosomes (LYs; Mullock et al., 1998).

\section{Endosomal Flux Is Regulated by Cholesterol Content}

Cholesterol fulfils central regulatory roles within the endosomal system. The lipid affects membrane curvature (Chen and Rand, 1997; Lee et al., 2020), thickness (de Meyer and Smit, 2009), fluidity (Cooper, 1978), and lipid microdomains (Sobo et al., 2007). It thereby regulates recruitment of integral and peripheral membrane proteins to lipid rafts and raft-like clusters (Melkonian et al., 1999; Levental et al., 2010; Lorent et al., 2017). This in turn is essential to endosomal flux, as there are continuous

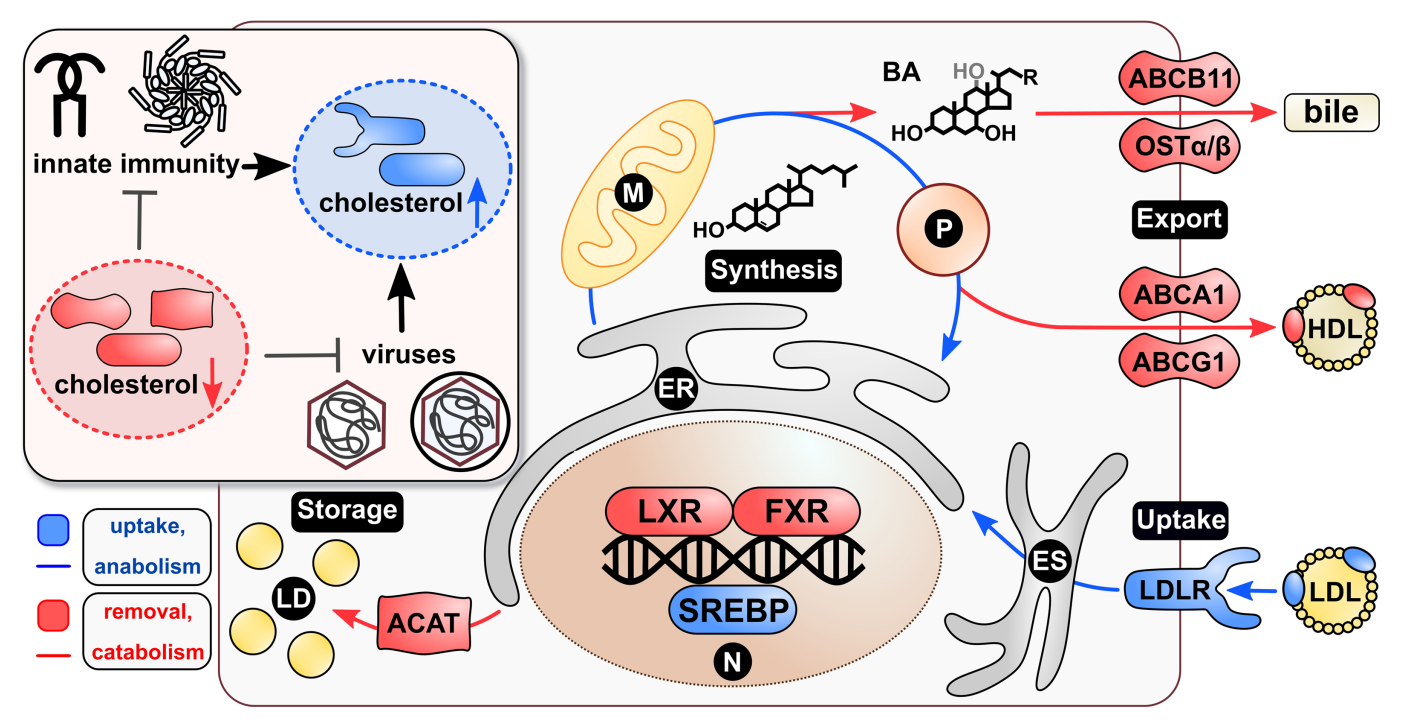

FIGURE 1 | Viruses and innate immunity shift the cholesterol homeostasis to the side of anabolism and uptake. Maintenance of the cellular cholesterol homeostasis is transcriptionally controlled via SREBPs and LXR/FXR acting as transcription factors. The first induce uptake and anabolism, whereas the latter induce removal and catabolism of cholesterol. Specifically, SREBPs induce the expression of LDLR leading to cholesterol uptake via LDL. This is then shuttled via the ES to the ER to be available in the cell. Further, they induce ER-, P-, and M-mediated de novo synthesis of the lipid. Once excess cholesterol is present in a cell, LXR induces direct cholesterol exporters, such as ABCA1/G1 leading to HDL synthesis. Secondly, LXR primes P- and M-mediated cholesterol derivatization via BA, which are exported by FXR-induced ABCB11 and OST $\alpha / \beta$. A third way of removing cholesterol from a cell is the ACAT-dependent storage of cholesterol esters in LDs. Interestingly, both viruses and innate immunity seem to be inhibited by withdrawal of cellular cholesterol. Similarly, both seem to induce mechanisms resulting in elevated cellular cholesterol, thus leading to a strong intertwinement with respect to the requirement of the lipid. Blue coloring=cholesterol uptake or anabolism; red coloring=cholesterol removal or catabolism. BA, bile acids; ER, endoplasmic reticulum; ES, endosomal system; LD, lipid droplets; M, mitochondrion; P, peroxisome; $\mathrm{N}$, nucleus. 
vesicular fission and fusion events. The latter are mainly regulated via soluble NSF attachment protein receptors (SNAREs). Both clustering and activity hereof is enhanced by cholesterol (Lang et al., 2001; Milovanovic et al., 2015; Stratton et al., 2016), which renders the lipid being intertwined with the fate of vesicular fusion. On the other hand, endosomal cholesterol also regulates and is regulated by dynamin-mediated vesicle fission (Robinet et al., 2006; Anderson et al., 2021) and is required for ESCRT-mediated ILV scission (Kobayashi et al., 2002; Boura et al., 2012; Bissig and Gruenberg, 2013). This strict regulation of membrane fusion and fission by cholesterol is accompanied by directed trafficking of endosomes along microtubules in the process of their maturation. Here, high endosomal cholesterol concentrations leads to recruitment of the dynein/dynactin motor complex and thereby mediates retrograde vesicle transport (Jordens et al., 2001; Thakur et al., 2020). This finally serves the purpose guaranteeing a functional cholesterol trafficking to its destination.

\section{Cholesterol Distribution Is Mediated via the Endosomal System}

The endolysosomal systems marks the final destination for endocytosed cholesterol. From here on, the lipid will be re-distributed toward other organelles or toward the place of storage, which requires an intricate combination of shuttling proteins and organelle-organelle adaptor proteins. Once inside LEs or LYs, cholesterol is mobilized with the help of carrier proteins, such as lysosome-associated membrane glycoprotein 2 (LAMP2; Li and Pfeffer, 2016), saposins (Saps; LocatelliHoops et al., 2006), lysosomal integral membrane protein-2 (LIMP-2; Heybrock et al., 2019), or the NPC1/2 system (Watari et al., 1999; Infante et al., 2008). Subsequently, cholesterol is distributed to different organelles through organelle-organelle contact sites. Among these are synaptotagmin 7 (Syt7) mediating contacts to peroxisomes (Chu et al., 2015), mitofusin 2 (Mfn2), and vacuolar protein sorting-associated protein 13A (Vps13A) for mitochondria (Daniele et al., 2014; Muñoz-Braceras et al., 2019), NPC1, oxysterol binding protein-like 1A (ORP1L), Rab-interacting lysosomal protein (RILP), StAR-related lipid transfer domain-containing 3 (STARD3) for the endoplasmic reticulum (ER; Rocha et al., 2009; Wilhelm et al., 2017; Höglinger et al., 2019), or STARD4 for the PM (Iaea et al., 2017). This regulation then is essentially guaranteeing delivery of cholesterol to the ER, where it regulates SREBPs and is stored in LDs, to the site of BA synthesis and to ABCA1 exporting cholesterol, as reviewed elsewhere (Luo et al., 2017; Meng et al., 2020).

\section{ENDOSOMAL CHOLESTEROL TRAFFICKING AS SHARED FEATURE IN VIRAL INFECTIONS}

\section{Viral Attachment and Entry}

Primed by the characterization of the envelope of IAV (UHLER and GARD, 1954), it became apparent that cholesterol is a central component in a variety of viral envelopes
(Aloia et al., 1993; Funk et al., 2008; Bremer et al., 2009; Merz et al., 2011; Gerl et al., 2012; Carro and Damonte, 2013). On the host side, it aids in endocytosis (Rodal et al., 1999) and therefore is required for viral internalization for a wide range of both enveloped and non-enveloped viruses (Ripa et al., 2021). Apart from endocytosed viruses, the lipid is also required for entry of enveloped viruses directly fusing with the PM, such as HIV (Carter et al., 2009) or Kaposi's sarcoma-associated herpesvirus (KSHV; Raghu et al., 2007). PM cholesterol therefore serves as first regulator in a viral life cycle, which is either supplied by ER-PM contact sites or ERC-PM contact sites. While various adaptors for ER-PM shuttling have been identified (Naito et al., 2019; Li et al., 2021), ERC-PM contacts present as rather enigmatic although evidently being similarly important (Hölttä-Vuori et al., 2002; Möbius et al., 2003; Garbarino et al., 2012; Iaea et al., 2017). Further elucidation of the latter and how it is modulated by viruses thus presents as important aspect of focus. After cholesterol-dependent steps in endocytosis, shuttling of the lipid within virus-containing endosomes further is important for the uncoating, and therefore for final cellular entry, of enveloped viruses, such as members of the Filoviridae family, IAV, HIV, SARS-CoV-2, and Alphaviruses (Schroeder, 2010; Carette et al., 2011; Côté et al., 2011; Garcia-Dorival et al., 2020; Martyna et al., 2020; Sousa et al., 2020). This process is reported to be mediated via cholesterol-shuttling proteins, such as NPC1. Besides the latter, also lysosomeassociated membrane glycoprotein 1 (LAMP1), which also is capable of binding cholesterol, has been described to facilitate the cellular entry of Lassa virus (LASV; Hulseberg et al., 2018). As these entry factors represent cholesterol-binding proteins and facilitate viral entry, an involvement of the lipid in, for example, facilitating endosomal escape is evident. Advances in how endosomal cholesterol transport machineries affect different viruses therefore also enhances knowledge on possible entry inhibitors.

\section{Viral Replication}

After entry, cholesterol similarly strictly regulates viral replication in manifold cases. For the buildup of the characteristic membranous web around the ER being crucial for $\mathrm{HCV}$ replication (Egger et al., 2002; Moradpour et al., 2003), the virus makes use of LE/LYs contact sites and cholesterol trafficking mediated by STARD3, ORP1L, and NPC1 (Stoeck et al., 2018). This recruitment appears to be a similarly important feature for the closely related Flaviviruses (Wang H. et al., 2014; Merino-Ramos et al., 2016; Neufeldt et al., 2018). Although not being known for web formation, the more distantly related CVB3, EMCV and Aichi virus (AiV) seem to share the importance of cholesterol being shuttled to the ER (Albulescu et al., 2015; Ishikawa-Sasaki et al., 2018).

\section{Viral Morphogenesis and Egress}

On the side of viral release, virtually all routes of viral egress, including autophagy-induced cell lysis, strictly depend on membrane fusion or fission events. Efficient cholesterol distribution herein is required for the secretory pathway, 


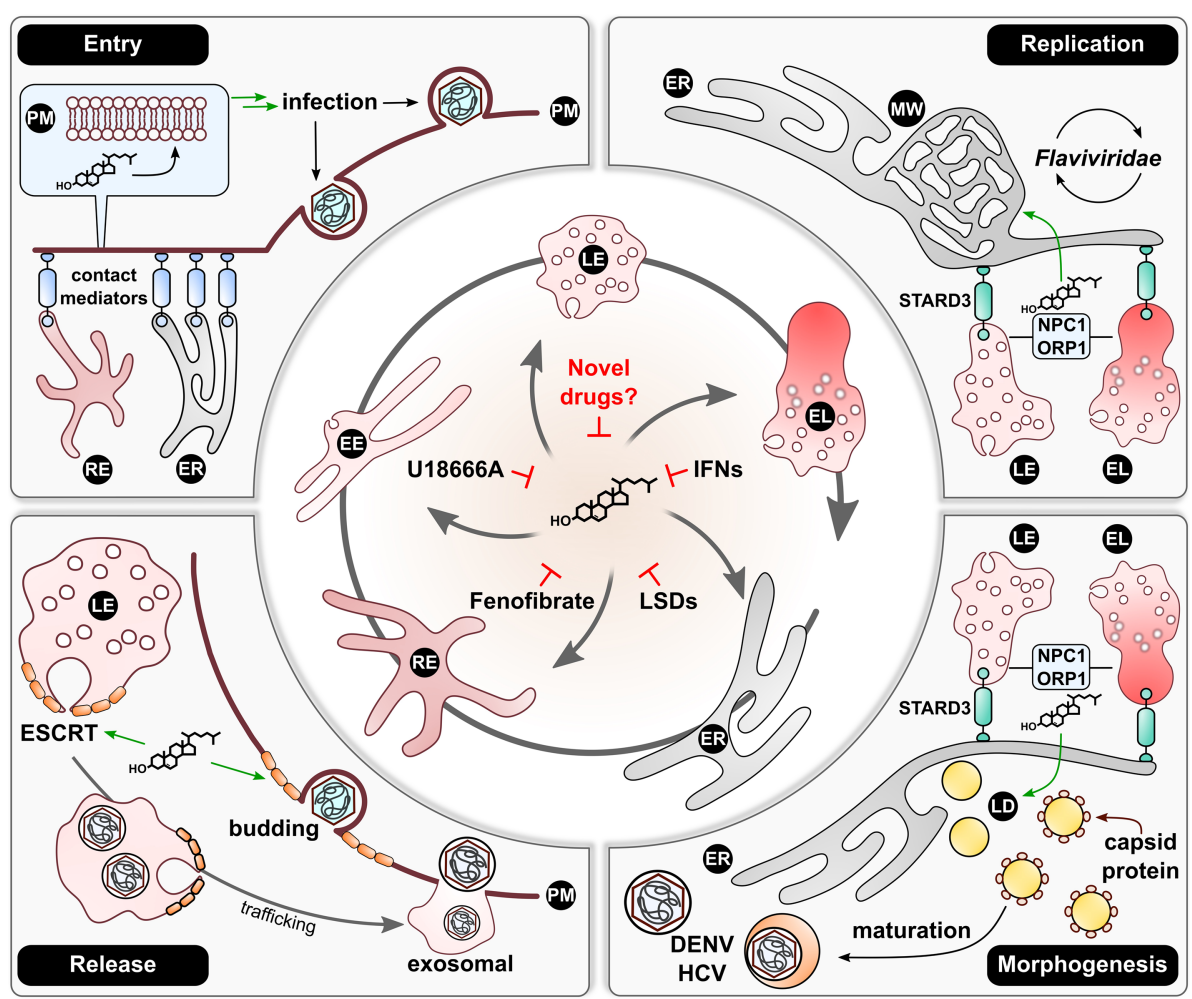

FIGURE 2 | An efficient endosomal re-distribution of cholesterol is required for sustainment of viral life cycles. The endosomal system contains central organelles maintaining cellular cholesterol distribution. Viruses thus make use of these lipid-mobilizing mechanisms to ensure sufficient spatial cholesterol supply during their life cycles. For infection or re-infection, viruses require local cholesterol accumulations at the site of PM fusion or endocytosis. These are fueled by the lipid being transported from the ER or REs, which is dependent on various adaptors establishing respective contact sites to the PM. After infection, especially members of the Flaviviridae family were described to induce a cholesterol-enriched MW or replication organelles at the ER. Lipid supply hereby is enhanced by recruiting LEs and ELs to the ER via STARD3 with subsequent cholesterol shuttling in an NPC1/ORP1-dependent manner. Similarly, well characterized for this virus family is the dependency on LDs for morphogenesis. Here, DENV and HCV rely on a comparable mechanism involving LEs and ELs for providing ER cholesterol and therefore LD morphogenesis. Lastly, various studies demonstrated that a broad spectrum of viruses is reliant on the ESCRT machinery for viral release either via the LEmediated exosomal route or via ESCRT-mediated PM budding. The activity of ESCRT-III stands in close relationship with the local cholesterol concentration, which renders the lipid fulfilling a vital role in the production of viral progeny. Once an efficient cholesterol distribution is perturbed, viral life cycles tend to collapse. This was made use of in the past by inducing cholesterol accumulations by application of U18666A, IFNs, or Fenofibrate. Additionally, the artificial induction of LSDs yielded comparable effects. Thus, this mechanism could present as essential target to novel broad-spectrum antivirals. EE, early endosome; EL, endolysosome; ER, endoplasmic reticulum; IFNs, interferons; LD, lipid droplet; LE, late endosome; LSDs, lysosomal storage disorders; MW, membranous web; RE, recycling endosome; PM, plasma membrane.

the exosomal pathway, or direct budding from the plasma membrane (Wang et al., 2000; Ridsdale et al., 2006; Kobuna et al., 2010; Boura et al., 2012). Here, the main focus of research was set on MVBs and related protein complexes. Blockage of the NPC1/2 system, for example, inhibits MVB-dependent HCV release (Elgner et al., 2016) and the life cycle of both DENV and ZIKV (Poh et al., 2012; Sabino et al., 2019). This similarly could expose weaknesses of other viruses as $\mathrm{HBV}$, hepatitis A virus (HAV), and HEV (Lambert et al., 2007; Hoffmann et al., 2013; Nagashima et al., 2014; González-López et al., 2018) or other enteric viruses (Zhang et al., 2021), as they rely on a comparable release pathway. Apart from MVB-located ESCRT, also the budding process of HIV on PMs needs to be regarded (Sundquist and Kräusslich, 2012). Specifically, the requirement of ESCRT-III renders the need of local cholesterol clustering (Morita et al., 2011; Yandrapalli et al., 2016). Here again, ERC-PM contacts may come into play as discussed above.
On the other hand, studies point into the direction that NPC1 and lysosomal recruitment to the cell periphery may be involved in maintaining cholesterol supply to these sites of release (Tang et al., 2009; Cinti et al., 2017). These mechanisms directly link endosomal maturation, which relies on cholesterol, to viral release. Which role lysosomes fulfill in the role of virion production, however, needs to be further studied. Reason for this is growing evidence that some viruses, for example, $\beta$-Coronaviruses (Ghosh et al., 2020), make use of these organelles for viral release, therefore bringing cholesterolregulated endolysosomal maturation into focus.

\section{Peroxisomes and Mitochondria}

Lastly, organelles being majorly involved in the cholesterol metabolism per se need to be regarded. Both peroxisomes and mitochondria are essential in anabolism and derivatization of cholesterol (Kovacs et al., 2002). As pointed out earlier, cholesterol 
has the potential to control innate immunity with respect to IFN responses. Additionally, there is growing awareness that its anabolism and its derivatization into oxysterols or BAs mediate central aspects of inflammation (Spann et al., 2012; Perucha et al., 2019; Willinger, 2019; Cardoso and Perucha, 2021). How and if cholesterol trafficking to these organelles affects these mechanisms remains largely elusive so far. One hint can be found in DENV being reported to cleave Mfns (Yu et al., 2015). This in turn could diminish mitochondrial cholesterol levels and subsequently reduce inflammasome activity (Ichinohe et al., 2013). Elucidation of these processes therefore could present useful with respect to other viruses and their relation to inflammatory responses.

\section{CONCLUSION AND OUTLOOK}

As presented above and in Figure 2, viruses indeed seem to rely on a certain level of cholesterol within a cell to ensure an ongoing life cycle and therefore perturb the host metabolome. However, by simply reducing cellular cholesterol in an antiviral approach, one could also potentially dampen the immune system, as evidenced previously (Bahrami et al., 2018; Koike et al., 2021). By having a closer look on cholesterol shuttling within the endosomal system, it becomes apparent that viruses strongly rely on an intact lipid flux. Thus, the key to finding a real pan-antiviral strategy may come down to withdrawing cholesterol from where it is needed for viral maintenance rather than reducing it globally. This very mechanism could be achieved by inducing a deliberate accumulation of cholesterol within the endosomal system. Here, recent studies identified this as restrictive action against IAV in the context of an IFN response (Kühnl et al., 2018) and against $\mathrm{HEV}$ as a consequence of

\section{REFERENCES}

Albulescu, L., Wubbolts, R., van Kuppeveld, F. J. M., and Strating, J. R. P. M. (2015). Cholesterol shuttling is important for RNA replication of coxsackievirus B3 and encephalomyocarditis virus. Cell. Microbiol. 17, 1144-1156. doi: $10.1111 / \mathrm{cmi} .12425$

Aloia, R. C., Tian, H., and Jensen, F. C. (1993). Lipid composition and fluidity of the human immunodeficiency virus envelope and host cell plasma membranes. Proc. Natl. Acad. Sci. U. S. A. 90, 5181-5185. doi: 10.1073/pnas.90.11.5181

Ananthanarayanan, M., Balasubramanian, N., Makishima, M., Mangelsdorf, D. J., and Suchy, F. J. (2001). Human bile salt export pump promoter is transactivated by the farnesoid X receptor/bile acid receptor. J. Biol. Chem. 276, 28857-28865. doi: $10.1074 /$ jbc.M011610200

Anderson, R. H., Sochacki, K. A., Vuppula, H., Scott, B. L., Bailey, E. M., Schultz, M. M., et al. (2021). Sterols lower energetic barriers of membrane bending and fission necessary for efficient clathrin mediated endocytosis. bioRxiv [Preprint]. doi: 10.1101/2021.01.31.428633

Anggakusuma, Romero-Brey, I., Berger, C., Colpitts, C. C., Boldanova, T., Engelmann, M., et al. (2015). Interferon-inducible cholesterol-25-hydroxylase restricts hepatitis $\mathrm{C}$ virus replication through blockage of membranous web formation. Hepatology 62, 702-714. doi: 10.1002/hep.27913

Bahrami, A., Parsamanesh, N., Atkin, S. L., Banach, M., and Sahebkar, A. (2018). Effect of statins on toll-like receptors: a new insight to pleiotropic effects. Pharmacol. Res. 135, 230-238. doi: 10.1016/j.phrs.2018.08.014

Ballatori, N., Christian, W. V., Lee, J. Y., Dawson, P. A., Soroka, C. J., Boyer, J. L., et al. (2005). OSTalpha-OSTbeta: a major basolateral bile acid and steroid heavy cholesterol uptake and Fenofibrate application (Glitscher et al., 2021). Similarly, this could explain the broad antiviral effect of lysosomotropic drugs, such as U18666A (Kuzu et al., 2017). While the tools at hand already present promising treatment options against viral infections, more research is required in assessing adverse effects such as lysosomal storage diseases. Thus, advances in clarifying molecular mechanisms and regulators in endosomal cholesterol shuttling may finally lead to the discovery of a tolerable, pan-antiviral therapy.

\section{AUTHOR CONTRIBUTIONS}

EH and MG: conceptualization. MG: writing - original draft preparation and visualization. EH: writing - review and editing, supervision, project administration, and funding acquisition. All authors contributed to the article and approved the submitted version.

\section{FUNDING}

This work was supported with a grant by the LOEWE Center DRUID (Novel Drug Targets against Poverty-Related and Neglected Tropical Infectious Diseases; project D2).

\section{ACKNOWLEDGMENTS}

The authors thank the LOEWE Center DRUID (Novel Drug Targets against Poverty-Related and Neglected Tropical Infectious Diseases; project D2) for financial support. The authors further thank Tobias Zahn for proofreading and discussing aspects of the article.

transporter in human intestinal, renal, and biliary epithelia. Hepatology 42, 1270-1279. doi: 10.1002/hep.20961

Barba, G., Harper, F., Harada, T., Kohara, M., Goulinet, S., Matsuura, Y., et al. (1997). Hepatitis C virus core protein shows a cytoplasmic localization and associates to cellular lipid storage droplets. Proc. Natl. Acad. Sci. U. S. A. 94, 1200-1205. doi: 10.1073/pnas.94.4.1200

Bissig, C., and Gruenberg, J. (2013). Lipid sorting and multivesicular endosome biogenesis. Cold Spring Harb. Perspect. Biol. 5:a016816. doi: 10.1101/cshperspect. a016816

Blanc, M., Hsieh, W. Y., Robertson, K. A., Kropp, K. A., Forster, T., Shui, G., et al. (2013). The transcription factor STAT-1 couples macrophage synthesis of 25-hydroxycholesterol to the interferon antiviral response. Immunity 38, 106-118. doi: 10.1016/j.immuni.2012.11.004

Blanchet, M., Le, Q.-T., Seidah, N. G., and Labonté, P. (2016). Statins can exert dual, concentration dependent effects on HCV entry in vitro. Antivir. Res. 128, 43-48. doi: 10.1016/j.antiviral.2016.02.006

Boadu, E., and Francis, G. A. (2006). The role of vesicular transport in ABCA1dependent lipid efflux and its connection with NPC pathways. J. Mol. Med. 84, 266-275. doi: 10.1007/s00109-005-0001-9

Boadu, E., Nelson, R. C., and Francis, G. A. (2012). ABCA1-dependent mobilization of lysosomal cholesterol requires functional Niemann-Pick C2 but not Niemann-Pick C1 protein. Biochim. Biophys. Acta 1821, 396-404. doi: 10.1016/j.bbalip.2011.11.013

Boulant, S., Targett-Adams, P., and McLauchlan, J. (2007). Disrupting the association of hepatitis $\mathrm{C}$ virus core protein with lipid droplets correlates with a loss in production of infectious virus. J. Gen. Virol. 88, 2204-2213. doi: 10.1099/vir.0.82898-0 
Boura, E., Ivanov, V., Carlson, L.-A., Mizuuchi, K., and Hurley, J. H. (2012). Endosomal sorting complex required for transport (ESCRT) complexes induce phase-separated microdomains in supported lipid bilayers. J. Biol. Chem. 287, 28144-28151. doi: 10.1074/jbc.M112.378646

Bremer, C. M., Bung, C., Kott, N., Hardt, M., and Glebe, D. (2009). Hepatitis $\mathrm{B}$ virus infection is dependent on cholesterol in the viral envelope. Cell. Microbiol. 11, 249-260. doi: 10.1111/j.1462-5822.2008.01250.x

Burd, C., and Cullen, P. J. (2014). Retromer: a master conductor of endosome sorting. Cold Spring Harb. Perspect. Biol. 6:a016774. doi: 10.1101/cshperspect. a016774

Cardoso, D., and Perucha, E. (2021). Cholesterol metabolism: a new molecular switch to control inflammation. Clin. Sci. 135, 1389-1408. doi: 10.1042/ CS20201394

Carette, J. E., Raaben, M., Wong, A. C., Herbert, A. S., Obernosterer, G., Mulherkar, N., et al. (2011). Ebola virus entry requires the cholesterol transporter Niemann-Pick C1. Nature 477, 340-343. doi: 10.1038/nature 10348

Carro, A. C., and Damonte, E. B. (2013). Requirement of cholesterol in the viral envelope for dengue virus infection. Virus Res. 174, 78-87. doi: 10.1016/j. virusres.2013.03.005

Carter, G. C., Bernstone, L., Sangani, D., Bee, J. W., Harder, T., and James, W. (2009). HIV entry in macrophages is dependent on intact lipid rafts. Virology 386, 192-202. doi: 10.1016/j.virol.2008.12.031

Chen, Z., and Rand, R. P. (1997). The influence of cholesterol on phospholipid membrane curvature and bending elasticity. Biophys. J. 73, 267-276. doi: 10.1016/S0006-3495(97)78067-6

Chen, Y., Wang, S., Yi, Z., Tian, H., Aliyari, R., Li, Y., et al. (2014). Interferoninducible cholesterol-25-hydroxylase inhibits hepatitis $\mathrm{C}$ virus replication via distinct mechanisms. Sci. Rep. 4:7242. doi: 10.1038/srep07242

Cheng, D., Chang, C. C., Qu, X., and Chang, T. Y. (1995). Activation of acylcoenzyme A:cholesterol acyltransferase by cholesterol or by oxysterol in a cell-free system. J. Biol. Chem. 270, 685-695. doi: 10.1074/jbc.270.2.685

Chiang, J. Y. L. (2015). Negative feedback regulation of bile acid metabolism: impact on liver metabolism and diseases. Hepatology 62, 1315-1317. doi: 10.1002/hep.27964

Chu, B.-B., Liao, Y.-C., Qi, W., Xie, C., Du, X., Wang, J., et al. (2015). Cholesterol transport through lysosome-peroxisome membrane contacts. Cell 161, 291-306. doi: 10.1016/j.cell.2015.02.019

Cianciola, N. L., Greene, D. J., Morton, R. E., and Carlin, C. R. (2013). Adenovirus RID $\alpha$ uncovers a novel pathway requiring ORP1L for lipid droplet formation independent of NPC1. Mol. Biol. Cell 24, 3309-3325. doi: 10.1091/mbc.e12-10-0760

Cinti, A., Le Sage, V., Milev, M. P., Valiente-Echeverría, F., Crossie, C., Miron, M.-J., et al. (2017). HIV-1 enhances mTORC1 activity and repositions lysosomes to the periphery by co-opting Rag GTPases. Sci. Rep. 7:5515. doi: 10.1038/ s41598-017-05410-0

Civra, A., Cagno, V., Donalisio, M., Biasi, F., Leonarduzzi, G., Poli, G., et al. (2014). Inhibition of pathogenic non-enveloped viruses by 25-hydroxycholesterol and 27-hydroxycholesterol. Sci. Rep. 4:7487. doi: 10.1038/ srep07487

Civra, A., Francese, R., Gamba, P., Testa, G., Cagno, V., Poli, G., et al. (2018). 25-Hydroxycholesterol and 27-hydroxycholesterol inhibit human rotavirus infection by sequestering viral particles into late endosomes. Redox Biol. 19, 318-330. doi: 10.1016/j.redox.2018.09.003

Claude-Taupin, A., Jia, J., Mudd, M., and Deretic, V. (2017). Autophagy's secret life: secretion instead of degradation. Essays Biochem. 61, 637-647. doi: 10.1042/EBC20170024

Cooper, R. A. (1978). Influence of increased membrane cholesterol on membrane fluidity and cell function in human red blood cells. J. Supramol. Struct. 8, 413-430. doi: 10.1002/jss.400080404

Côté, M., Misasi, J., Ren, T., Bruchez, A., Lee, K., Filone, C. M., et al. (2011). Small molecule inhibitors reveal Niemann-Pick C1 is essential for Ebola virus infection. Nature 477, 344-348. doi: 10.1038/nature10380

Daniele, T., Hurbain, I., Vago, R., Casari, G., Raposo, G., Tacchetti, C., et al. (2014). Mitochondria and melanosomes establish physical contacts modulated by Mfn2 and involved in organelle biogenesis. Curr. Biol. 24, 393-403. doi: 10.1016/j.cub.2014.01.007

de Clercq, E., and Li, G. (2016). Approved antiviral drugs over the past 50 years. Clin. Microbiol. Rev. 29, 695-747. doi: 10.1128/CMR.00102-15 de La Roche, M., Hamilton, C., Mortensen, R., Jeyaprakash, A. A., Ghosh, S., and Anand, P. K. (2018). Trafficking of cholesterol to the ER is required for NLRP3 inflammasome activation. J. Cell Biol. 217, 3560-3576. doi: $10.1083 /$ jcb.201709057

de Meyer, F., and Smit, B. (2009). Effect of cholesterol on the structure of a phospholipid bilayer. Proc. Natl. Acad. Sci. U. S. A. 106, 3654-3658. doi: 10.1073/pnas.0809959106

Deng, R., Yang, D., Yang, J., and Yan, B. (2006). Oxysterol 22(R)-hydroxycholesterol induces the expression of the bile salt export pump through nuclear receptor farsenoid X receptor but not liver X receptor. J. Pharmacol. Exp. Ther. 317, 317-325. doi: 10.1124/jpet.105.097758

Dias, S. S. G., Soares, V. C., Ferreira, A. C., Sacramento, C. Q., Fintelman-Rodrigues, N., Temerozo, J. R., et al. (2020). Lipid droplets fuel SARS-CoV-2 replication and production of inflammatory mediators. PLoS Pathog. 16:e1009127. doi: 10.1371/journal.ppat.1009127

Ding, N., Liu, N., Yang, L., Han, X., Lin, L., and Long, Y. (2020). ABCA1 plays an anti-inflammatory role by affecting TLR4 at the feto-maternal interface. Life Sci. 259:118390. doi: 10.1016/j.lfs.2020.118390

Domingo, E., de Ávila, A. I., Gallego, I., Sheldon, J., and Perales, C. (2019). Viral fitness: history and relevance for viral pathogenesis and antiviral interventions. Pathog. Dis. 77:ftz021. doi: 10.1093/femspd/ftz021

Egger, D., Wölk, B., Gosert, R., Bianchi, L., Blum, H. E., Moradpour, D., et al. (2002). Expression of hepatitis $C$ virus proteins induces distinct membrane alterations including a candidate viral replication complex. J. Virol. 76, 5974-5984. doi: 10.1128/JVI.76.12.5974-5984.2002

Elgner, F., Ren, H., Medvedev, R., Ploen, D., Himmelsbach, K., Boller, K., et al. (2016). The intracellular cholesterol transport inhibitor U18666A inhibits the exosome-dependent release of mature hepatitis C virus. J. Virol. 90, 11181-11196. doi: 10.1128/JVI.01053-16

Forman, B. M., Goode, E., Chen, J., Oro, A. E., Bradley, D. J., Perlmann, T., et al. (1995). Identification of a nuclear receptor that is activated by farnesol metabolites. Cell 81, 687-693. doi: 10.1016/0092-8674(95)90530-8

Frankel, E. B., and Audhya, A. (2018). ESCRT-dependent cargo sorting at multivesicular endosomes. Semin. Cell Dev. Biol. 74, 4-10. doi: 10.1016/j. semcdb.2017.08.020

Funk, A., Mhamdi, M., Hohenberg, H., Heeren, J., Reimer, R., Lambert, C., et al. (2008). Duck hepatitis B virus requires cholesterol for endosomal escape during virus entry. J. Virol. 82, 10532-10542. doi: 10.1128/JVI. 00422-08

Ganesan, D., and Cai, Q. (2021). Understanding amphisomes. Biochem. J. 478, 1959-1976. doi: 10.1042/BCJ20200917

Garbarino, J., Pan, M., Chin, H. F., Lund, F. W., Maxfield, F. R., and Breslow, J. L. (2012). STARD4 knockdown in HepG2 cells disrupts cholesterol trafficking associated with the plasma membrane, ER, and ERC. J. Lipid Res. 53, 2716-2725. doi: 10.1194/jlr.M032227

Garcia-Dorival, I., Ángel Cuesta-Geijo, M., Barrado-Gil, L., Galindo, I., Urquiza, J., Del Puerto, A., et al. (2020). Identification of NPC1 as a novel SARS-CoV-2 intracellular target. bioRxiv [Preprint]. doi: 10.1101/2020.12.19.423584

Geelen, M., Gibson, D., and Rodwell, V. (1986). Hydroxymethylglutaryl-CoA reductase - the rate-limiting enzyme of cholesterol biosynthesis. FEBS Lett. 201, 183-186. doi: 10.1016/0014-5793(86)80604-4

Gelissen, I. C., Harris, M., Rye, K.-A., Quinn, C., Brown, A. J., Kockx, M., et al. (2006). ABCA1 and ABCG1 synergize to mediate cholesterol export to apoA-I. Arterioscler. Thromb. Vasc. Biol. 26, 534-540. doi: 10.1161/01. ATV.0000200082.58536.e1

Gerl, M. J., Sampaio, J. L., Urban, S., Kalvodova, L., Verbavatz, J.-M., Binnington, B., et al. (2012). Quantitative analysis of the lipidomes of the influenza virus envelope and MDCK cell apical membrane. J. Cell Biol. 196, 213-221. doi: 10.1083/jcb.201108175

Ghosh, S., Dellibovi-Ragheb, T. A., Kerviel, A., Pak, E., Qiu, Q., Fisher, M., et al. (2020). $\beta$-Coronaviruses use lysosomes for egress instead of the biosynthetic secretory pathway. Cell 183, 1520.e14-1535.e14. doi: 10.1016/j. cell.2020.10.039

Glitscher, M., Martín, D. H., Woytinek, K., Schmidt, B., Tabari, D., Scholl, C., et al. (2021). Targeting cholesterol metabolism as efficient antiviral strategy against the hepatitis E virus. Cell. Mol. Gastroenterol. Hepatol. 12, 159-180. doi: $10.1016 /$ j.jcmgh.2021.02.002

González-López, O., Rivera-Serrano, E. E., Hu, F., Hensley, L., McKnight, K. L., Ren, J., et al. (2018). Redundant late domain functions of tandem VP2 
YPX3L motifs in nonlytic cellular egress of quasi-enveloped hepatitis A virus. J. Virol. 92, e01308-e01318. doi: 10.1128/JVI.01308-18

Gorabi, A. M., Kiaie, N., Bianconi, V., Jamialahmadi, T., Al-Rasadi, K., Johnston, T. P., et al. (2020). Antiviral effects of statins. Prog. Lipid Res. 79:101054. doi: 10.1016/j.plipres.2020.101054

Gordon, P. B., and Seglen, P. O. (1988). Prelysosomal convergence of autophagic and endocytic pathways. Biochem. Biophys. Res. Commun. 151, 40-47. doi: 10.1016/0006-291X(88)90556-6

Guo, L., Chen, C.-H., Zhang, L.-L., Cao, X.-J., Ma, Q.-L., Deng, P., et al. (2015). IRAK1 mediates TLR4-induced ABCA1 downregulation and lipid accumulation in VSMCs. Cell Death Dis. 6:e1949. doi: 10.1038/cddis.2015.212

Guo, C., Chi, Z., Jiang, D., Xu, T., Yu, W., Wang, Z., et al. (2018). Cholesterol homeostatic regulator SCAP-SREBP2 integrates NLRP3 inflammasome activation and cholesterol biosynthetic signaling in macrophages. Immunity 49, 842.e7-856.e7. doi: 10.1016/j.immuni.2018.08.021

Gupta, S., Pandak, W. M., and Hylemon, P. B. (2002). LXR alpha is the dominant regulator of CYP7A1 transcription. Biochem. Biophys. Res. Commun. 293, 338-343. doi: 10.1016/S0006-291X(02)00229-2

Hao, J., Zhang, Y., Lv, X., Xu, N., Liu, Q., Zhao, S., et al. (2013). IFN- $\gamma$ induces lipogenesis in mouse mesangial cells via the JAK2/STAT1 pathway. Am. J. Phys. Cell Physiol. 304, C760-C767. doi: 10.1152/ajpcell.00352.2012

Hessvik, N. P., and Llorente, A. (2018). Current knowledge on exosome biogenesis and release. Cell. Mol. Life Sci. 75, 193-208. doi: 10.1007/s00018-017-2595-9

Heybrock, S., Kanerva, K., Meng, Y., Ing, C., Liang, A., Xiong, Z.-J., et al. (2019). Lysosomal integral membrane protein-2 (LIMP-2/SCARB2) is involved in lysosomal cholesterol export. Nat. Commun. 10:3521. doi: 10.1038/ s41467-019-11425-0

Hoffmann, J., Boehm, C., Himmelsbach, K., Donnerhak, C., Roettger, H., Weiss, T. S., et al. (2013). Identification of $\alpha$-taxilin as an essential factor for the life cycle of hepatitis B virus. J. Hepatol. 59, 934-941. doi: 10.1016/j. jhep.2013.06.020

Höglinger, D., Burgoyne, T., Sanchez-Heras, E., Hartwig, P., Colaco, A., Newton, J., et al. (2019). NPC1 regulates ER contacts with endocytic organelles to mediate cholesterol egress. Nat. Commun. 10:4276. doi: 10.1038/ s41467-019-12152-2

Hölttä-Vuori, M., Tanhuanpää, K., Möbius, W., Somerharju, P., and Ikonen, E. (2002). Modulation of cellular cholesterol transport and homeostasis by Rab11. Mol. Biol. Cell 13, 3107-3122. doi: 10.1091/mbc.E02-01-0025

Horner, S. M., Liu, H. M., Park, H. S., Briley, J., and Gale, M. (2011). Mitochondrial-associated endoplasmic reticulum membranes (MAM) form innate immune synapses and are targeted by hepatitis C virus. Proc. Natl. Acad. Sci. U. S. A. 108, 14590-14595. doi: 10.1073/pnas.1110133108

Hulseberg, C. E., Fénéant, L., Szymańska, K. M., and White, J. M. (2018). Lamp1 increases the efficiency of lassa virus infection by promoting fusion in less acidic endosomal compartments. MBio 9, e01818-e01817. doi: 10.1128/ mBio.01818-17

Husebye, H., Halaas, Ø., Stenmark, H., Tunheim, G., Sandanger, Ø., Bogen, B., et al. (2006). Endocytic pathways regulate toll-like receptor 4 signaling and link innate and adaptive immunity. EMBO J. 25, 683-692. doi: 10.1038/ sj.emboj.7600991

Iaea, D. B., Mao, S., Lund, F. W., and Maxfield, F. R. (2017). Role of STARD4 in sterol transport between the endocytic recycling compartment and the plasma membrane. Mol. Biol. Cell 28, 1111-1122. doi: 10.1091/mbc.e16-07-0499

Ichinohe, T., Yamazaki, T., Koshiba, T., and Yanagi, Y. (2013). Mitochondrial protein mitofusin 2 is required for NLRP3 inflammasome activation after RNA virus infection. Proc. Natl. Acad. Sci. U. S. A. 110, 17963-17968. doi: 10.1073/pnas.1312571110

Im, S.-S., Yousef, L., Blaschitz, C., Liu, J. Z., Edwards, R. A., Young, S. G., et al. (2011). Linking lipid metabolism to the innate immune response in macrophages through sterol regulatory element binding protein-1a. Cell Metab. 13, 540-549. doi: 10.1016/j.cmet.2011.04.001

Infante, R. E., Wang, M. L., Radhakrishnan, A., Kwon, H. J., Brown, M. S., and Goldstein, J. L. (2008). NPC2 facilitates bidirectional transfer of cholesterol between NPC1 and lipid bilayers, a step in cholesterol egress from lysosomes. Proc. Natl. Acad. Sci. U. S. A. 105, 15287-15292. doi: 10.1073/pnas.0807328105

Ishii, N., Funami, K., Tatematsu, M., Seya, T., and Matsumoto, M. (2014). Endosomal localization of TLR8 confers distinctive proteolytic processing on human myeloid cells. J. Immun. 193, 5118-5128. doi: 10.4049/ jimmunol.1401375
Ishikawa-Sasaki, K., Nagashima, S., Taniguchi, K., and Sasaki, J. (2018). Model of OSBP-mediated cholesterol supply to aichi virus RNA replication sites involving protein-protein interactions among viral proteins, ACBD3, OSBP, VAP-A/B, and SAC1. J. Virol. 92, e01952-e01917. doi: 10.1128/JVI.01952-17

Janowski, B. A., Willy, P. J., Devi, T. R., Falck, J. R., and Mangelsdorf, D. J. (1996). An oxysterol signalling pathway mediated by the nuclear receptor LXR alpha. Nature 383, 728-731. doi: 10.1038/383728a0

Jiang, H., White, E. J., Ríos-Vicil, C. I., Xu, J., Gomez-Manzano, C., and Fueyo, J. (2011). Human adenovirus type 5 induces cell lysis through autophagy and autophagy-triggered caspase activity. J. Virol. 85, 4720-4729. doi: 10.1128/ JVI.02032-10

Johnsen, I. B., Nguyen, T. T., Ringdal, M., Tryggestad, A. M., Bakke, O., Lien, E., et al. (2006). Toll-like receptor 3 associates with c-Src tyrosine kinase on endosomes to initiate antiviral signaling. $E M B O ~ J .25,3335-3346$. doi: $10.1038 /$ sj.emboj.7601222

Jordens, I., Fernandez-Borja, M., Marsman, M., Dusseljee, S., Janssen, L., Calafat, J., et al. (2001). The Rab7 effector protein RILP controls lysosomal transport by inducing the recruitment of dynein-dynactin motors. Curr. Biol. 11, 1680-1685. doi: 10.1016/S0960-9822(01)00531-0

Jung, K., Wang, Q., Kim, Y., Scheuer, K., Zhang, Z., Shen, Q., et al. (2012). The effects of simvastatin or interferon- $\alpha$ on infectivity of human norovirus using a gnotobiotic pig model for the study of antivirals. PLoS One 7:e41619. doi: 10.1371/journal.pone.0041619

Kassam, A., Miao, B., Young, P. R., and Mukherjee, R. (2003). Retinoid X receptor (RXR) agonist-induced antagonism of farnesoid X receptor (FXR) activity due to absence of coactivator recruitment and decreased DNA binding. J. Biol. Chem. 278, 10028-10032. doi: 10.1074/jbc.M208312200

Kobayashi, T., Beuchat, M.-H., Chevallier, J., Makino, A., Mayran, N., Escola, J.-M., et al. (2002). Separation and characterization of late endosomal membrane domains. J. Biol. Chem. 277, 32157-32164. doi: 10.1074/jbc.M202838200

Kobuna, H., Inoue, T., Shibata, M., Gengyo-Ando, K., Yamamoto, A., Mitani, S., et al. (2010). Multivesicular body formation requires OSBP-related proteins and cholesterol. PLoS Genet. 6:e1001055. doi: 10.1371/journal.pgen.1001055

Koike, A., Tsujinaka, K., and Fujimori, K. (2021). Statins attenuate antiviral IFN- $\beta$ and ISG expression via inhibition of IRF3 and JAK/STAT signaling in poly(I:C)-treated hyperlipidemic mice and macrophages. FEBS J. 288, 4249-4266. doi: 10.1111/febs.15712

Kovacs, W. J., Olivier, L. M., and Krisans, S. K. (2002). Central role of peroxisomes in isoprenoid biosynthesis. Prog. Lipid Res. 41, 369-391. doi: 10.1016/ S0163-7827(02)00002-4

Kühnl, A., Musiol, A., Heitzig, N., Johnson, D. E., Ehrhardt, C., Grewal, T., et al. (2018). Late endosomal/lysosomal cholesterol accumulation is a host cell-protective mechanism inhibiting endosomal escape of influenza A virus. MBio 9, e01345-e01318. doi: 10.1128/mBio.01345-18

Kuzu, O. F., Toprak, M., Noory, M. A., and Robertson, G. P. (2017). Effect of lysosomotropic molecules on cellular homeostasis. Pharmacol. Res. 117, 177-184. doi: 10.1016/j.phrs.2016.12.021

Lambert, C., Döring, T., and Prange, R. (2007). Hepatitis B virus maturation is sensitive to functional inhibition of ESCRT-III, Vps4, and gamma 2-adaptin. J. Virol. 81, 9050-9060. doi: 10.1128/JVI.00479-07

Landrier, J.-F., Eloranta, J. J., Vavricka, S. R., and Kullak-Ublick, G. A. (2006). The nuclear receptor for bile acids, FXR, transactivates human organic solute transporter-alpha and -beta genes. Am. J. Physiol. Gastrointest. Liver Physiol. 290, G476-G485. doi: 10.1152/ajpgi.00430.2005

Lang, T., Bruns, D., Wenzel, D., Riedel, D., Holroyd, P., Thiele, C., et al. (2001). SNAREs are concentrated in cholesterol-dependent clusters that define docking and fusion sites for exocytosis. EMBO J. 20, 2202-2213. doi: 10.1093/ emboj/20.9.2202

Lange, P. T., Jondle, C. N., Darrah, E. J., Johnson, K. E., and Tarakanova, V. L. (2019). LXR alpha restricts gammaherpesvirus reactivation from latently infected peritoneal cells. J. Virol. 93, e02071-e02018. doi: 10.1128/JVI.02071-18

Lange, P. T., Schorl, C., Sahoo, D., and Tarakanova, V. L. (2018). Liver X receptors suppress activity of cholesterol and fatty acid synthesis pathways to oppose gammaherpesvirus replication. MBio 9, e01115-e01118. doi: 10.1128/mBio.01115-18

Latz, E., Schoenemeyer, A., Visintin, A., Fitzgerald, K. A., Monks, B. G., Knetter, C. F., et al. (2004). TLR9 signals after translocating from the ER to CpG DNA in the lysosome. Nat. Immunol. 5, 190-198. doi: 10.1038/ ni1028 
Le Bras, A. (2018). Cholesterol-dependent inflammasome activation accelerates atherosclerosis. Nat. Rev. Cardiol. 15, 318-319. doi: 10.1038/s41569-018-0012-1

Lee, Y. K., Yu, E.-S., Ahn, D. J., and Ryu, Y.-S. (2020). Elasticity-driven membrane budding through cholesterol concentration on supported lipid monolayerbilayer junction. Adv. Mater. Interfaces 7:2000937. doi: 10.1002/admi. 202000937

Lehmann, J. M., Kliewer, S. A., Moore, L. B., Smith-Oliver, T. A., Oliver, B. B., $\mathrm{Su}$, J. L., et al. (1997). Activation of the nuclear receptor LXR by oxysterols defines a new hormone response pathway. J. Biol. Chem. 272, 3137-3140. doi: $10.1074 /$ jbc.272.6.3137

Lembo, D., Cagno, V., Civra, A., and Poli, G. (2016). Oxysterols: an emerging class of broad spectrum antiviral effectors. Mol. Asp. Med. 49, 23-30. doi: 10.1016/j.mam.2016.04.003

Lester, S. N., and Li, K. (2014). Toll-like receptors in antiviral innate immunity. J. Mol. Biol. 426, 1246-1264. doi: 10.1016/j.jmb.2013.11.024

Levental, I., Lingwood, D., Grzybek, M., Coskun, U., and Simons, K. (2010). Palmitoylation regulates raft affinity for the majority of integral raft proteins. Proc. Natl. Acad. Sci. U. S. A. 107, 22050-22054. doi: 10.1073/pnas. 1016184107

Li, J., and Pfeffer, S. R. (2016). Lysosomal membrane glycoproteins bind cholesterol and contribute to lysosomal cholesterol export. elife 5:e21635. doi: 10.7554/ eLife. 21635

Li, C., Qian, T., He, R., Wan, C., Liu, Y., and Yu, H. (2021). Endoplasmic reticulum-plasma membrane contact sites: regulators, mechanisms, and physiological functions. Front. Cell Dev. Biol. 9:627700. doi: 10.3389/ fcell.2021.627700

Li, Y., Shen, S., Ding, S., and Wang, L. (2018). Toll-like receptor 2 downregulates the cholesterol efflux by activating the nuclear factor- $\mathrm{\kappa B}$ pathway in macrophages and may be a potential therapeutic target for the prevention of atherosclerosis. Exp. Ther. Med. 15, 198-204. doi: 10.3892/etm.2017.5404

Li, Y., Xu, S., Jiang, B., Cohen, R. A., and Zang, M. (2013). Activation of sterol regulatory element binding protein and NLRP3 inflammasome in atherosclerotic lesion development in diabetic pigs. PLoS One 8:e67532. doi: 10.1371/journal.pone.0067532

Liu, S.-Y., Aliyari, R., Chikere, K., Li, G., Marsden, M. D., Smith, J. K., et al. (2013). Interferon-inducible cholesterol-25-hydroxylase broadly inhibits viral entry by production of 25-hydroxycholesterol. Immunity 38, 92-105. doi: 10.1016/j.immuni.2012.11.005

Locatelli-Hoops, S., Remmel, N., Klingenstein, R., Breiden, B., Rossocha, M., Schoeniger, M., et al. (2006). Saposin A mobilizes lipids from low cholesterol and high bis(monoacylglycerol)phosphate-containing membranes: patient variant Saposin A lacks lipid extraction capacity. J. Biol. Chem. 281, 32451-32460. doi: 10.1074/jbc.M607281200

Lorent, J. H., Diaz-Rohrer, B., Lin, X., Spring, K., Gorfe, A. A., Levental, K. R., et al. (2017). Structural determinants and functional consequences of protein affinity for membrane rafts. Nat. Commun. 8:1219. doi: 10.1038/ s41467-017-01328-3

Luo, J., Jiang, L., Yang, H., and Song, B.-L. (2017). Routes and mechanisms of post-endosomal cholesterol trafficking: a story that never ends. Traffic 18, 209-217. doi: 10.1111/tra.12471

Mackenzie, J. M., Khromykh, A. A., and Parton, R. G. (2007). Cholesterol manipulation by West Nile virus perturbs the cellular immune response. Cell Host Microbe 2, 229-239. doi: 10.1016/j.chom.2007.09.003

Marcello, A., Civra, A., Milan Bonotto, R., Nascimento Alves, L., Rajasekharan, S., Giacobone, C., et al. (2020). The cholesterol metabolite 27-hydroxycholesterol inhibits SARS-CoV-2 and is markedly decreased in COVID-19 patients. Redox Biol. 36:101682. doi: 10.1016/j.redox.2020.101682

Marquis, J.-F., Kapoustina, O., Langlais, D., Ruddy, R., Dufour, C. R., Kim, B.-H., et al. (2011). Interferon regulatory factor 8 regulates pathways for antigen presentation in myeloid cells and during tuberculosis. PLoS Genet. 7:e1002097. doi: 10.1371/journal.pgen.1002097

Martyna, A., Bahsoun, B., Madsen, J. J., Jackson, F. S. J. S., Badham, M. D., Voth, G. A., et al. (2020). Cholesterol alters the orientation and activity of the influenza virus M2 amphipathic helix in the membrane. J. Phys. Chem. B 124, 6738-6747. doi: 10.1021/acs.jpcb.0c03331

Melkonian, K. A., Ostermeyer, A. G., Chen, J. Z., Roth, M. G., and Brown, D. A. (1999). Role of lipid modifications in targeting proteins to detergent-resistant membrane rafts. Many raft proteins are acylated, while few are prenylated. J. Biol. Chem. 274, 3910-3917. doi: 10.1074/jbc.274.6.3910
Meng, Y., Heybrock, S., Neculai, D., and Saftig, P. (2020). Cholesterol handling in lysosomes and beyond. Trends Cell Biol. 30, 452-466. doi: 10.1016/j. tcb.2020.02.007

Merino-Ramos, T., Vázquez-Calvo, Á., Casas, J., Sobrino, F., Saiz, J.-C., and Martín-Acebes, M. A. (2016). Modification of the host cell lipid metabolism induced by hypolipidemic drugs targeting the acetyl coenzyme A carboxylase impairs West Nile virus replication. Antimicrob. Agents Chemother. 60, 307-315. doi: 10.1128/AAC.01578-15

Merz, A., Long, G., Hiet, M.-S., Brügger, B., Chlanda, P., Andre, P., et al. (2011). Biochemical and morphological properties of hepatitis $C$ virus particles and determination of their lipidome. J. Biol. Chem. 286, 3018-3032. doi: 10.1074/jbc.M110.175018

Milovanovic, D., Honigmann, A., Koike, S., Göttfert, F., Pähler, G., Junius, M., et al. (2015). Hydrophobic mismatch sorts SNARE proteins into distinct membrane domains. Nat. Commun. 6:5984. doi: 10.1038/ncomms6984

Mlera, L., Offerdahl, D. K., Dorward, D. W., Carmody, A., Chiramel, A. I., Best, S. M., et al. (2021). The liver X receptor agonist LXR 623 restricts flavivirus replication. Emerg. Microbes Infect. 10, 1378-1389. doi: 10.1080/22221751.2021.1947749

Möbius, W., van Donselaar, E., Ohno-Iwashita, Y., Shimada, Y., Heijnen, H. F. G., Slot, J. W., et al. (2003). Recycling compartments and the internal vesicles of multivesicular bodies harbor most of the cholesterol found in the endocytic pathway. Traffic 4, 222-231. doi: 10.1034/j.1600-0854.2003.00072.x

Monson, E. A., Crosse, K. M., Duan, M., Chen, W., O'Shea, R. D., Wakim, L. M., et al. (2021). Intracellular lipid droplet accumulation occurs early following viral infection and is required for an efficient interferon response. Nat. Commun. 12:4303. doi: 10.1038/s41467-021-24632-5

Moradpour, D., Gosert, R., Egger, D., Penin, F., Blum, H. E., and Bienz, K. (2003). Membrane association of hepatitis C virus nonstructural proteins and identification of the membrane alteration that harbors the viral replication complex. Antivir. Res. 60, 103-109. doi: 10.1016/j.antiviral.2003.08.017

Morita, E., Sandrin, V., McCullough, J., Katsuyama, A., Baci Hamilton, I., and Sundquist, W. I. (2011). ESCRT-III protein requirements for HIV-1 budding. Cell Host Microbe 9, 235-242. doi: 10.1016/j.chom.2011.02.004

Mouzannar, K., Fusil, F., Lacombe, B., Ollivier, A., Ménard, C., Lotteau, V., et al. (2019). Farnesoid X receptor- $\alpha$ is a proviral host factor for hepatitis $\mathrm{B}$ virus that is inhibited by ligands in vitro and in vivo. FASEB J. 33, 2472-2483. doi: 10.1096/f.201801181R

Mujawar, Z., Rose, H., Morrow, M. P., Pushkarsky, T., Dubrovsky, L., Mukhamedova, N., et al. (2006). Human immunodeficiency virus impairs reverse cholesterol transport from macrophages. PLoS Biol. 4:e365. doi: 10.1371/journal.pbio.0040365

Mullen, L., Ferdjani, J., and Sacre, S. (2015). Simvastatin inhibits toll-like receptor 8 (TLR8) signaling in primary human monocytes and spontaneous tumor necrosis factor production from rheumatoid synovial membrane cultures. Mol. Med. 21, 726-734. doi: 10.2119/molmed.2015.00154

Mullock, B. M., Bright, N. A., Fearon, C. W., Gray, S. R., and Luzio, J. P. (1998). Fusion of lysosomes with late endosomes produces a hybrid organelle of intermediate density and is NSF dependent. J. Cell Biol. 140, 591-601. doi: $10.1083 /$ jcb.140.3.591

Muñoz-Braceras, S., Tornero-Écija, A. R., Vincent, O., and Escalante, R. (2019). VPS13A is closely associated with mitochondria and is required for efficient lysosomal degradation. Dis. Model. Mech. 12:dmm036681. doi: 10.1242/ dmm.036681

Murakami, K., Tenge, V. R., Karandikar, U. C., Lin, S.-C., Ramani, S., Ettayebi, K., et al. (2020). Bile acids and ceramide overcome the entry restriction for GII.3 human norovirus replication in human intestinal enteroids. Proc. Natl. Acad. Sci. U. S. A. 117, 1700-1710. doi: 10.1073/ pnas. 1910138117

Nagano, M., Toshima, J. Y., Siekhaus, D. E., and Toshima, J. (2019). Rab5mediated endosome formation is regulated at the trans-Golgi network. Commun. Biol. 2:419. doi: 10.1038/s42003-019-0670-5

Nagashima, S., Jirintai, S., Takahashi, M., Kobayashi, T., Tanggis, Nishizawa, T. et al. (2014). Hepatitis E virus egress depends on the exosomal pathway, with secretory exosomes derived from multivesicular bodies. J. Gen. Virol. 95, 2166-2175. doi: 10.1099/vir.0.066910-0

Naito, T., Ercan, B., Krshnan, L., Triebl, A., Koh, D. H. Z., Wei, F.-Y., et al. (2019). Movement of accessible plasma membrane cholesterol by the GRAMD1 lipid transfer protein complex. elife 8:e51401. doi: 10.7554/eLife.51401 
Negash, A. A., Ramos, H. J., Crochet, N., Lau, D. T. Y., Doehle, B., Papic, N., et al. (2013). IL-1 $\beta$ production through the NLRP3 inflammasome by hepatic macrophages links hepatitis $C$ virus infection with liver inflammation and disease. PLoS Pathog. 9:e1003330. doi: 10.1371/journal.ppat.1003330

Neufeldt, C. J., Cortese, M., Acosta, E. G., and Bartenschlager, R. (2018). Rewiring cellular networks by members of the Flaviviridae family. Nat. Rev. Microbiol. 16, 125-142. doi: 10.1038/nrmicro.2017.170

Nilsen, N. J., Deininger, S., Nonstad, U., Skjeldal, F., Husebye, H., Rodionov, D., et al. (2008). Cellular trafficking of lipoteichoic acid and toll-like receptor 2 in relation to signaling: role of CD14 and CD36. J. Leukoc. Biol. 84, 280-291. doi: 10.1189/jlb.0907656

Nishiya, T., Kajita, E., Miwa, S., and Defranco, A. L. (2005). TLR3 and TLR7 are targeted to the same intracellular compartments by distinct regulatory elements. J. Biol. Chem. 280, 37107-37117. doi: 10.1074/jbc.M504951200

Olzmann, J. A., and Carvalho, P. (2019). Dynamics and functions of lipid droplets. Nat. Rev. Mol. Cell Biol. 20, 137-155. doi: 10.1038/s41580-018-0085-z

Owusu, I. A., Quaye, O., Passalacqua, K. D., and Wobus, C. E. (2021). Egress of non-enveloped enteric RNA viruses. J. Gen. Virol. 102:001557. doi: 10.1099/ jgv.0.001557

Pascual-García, M., Rué, L., León, T., Julve, J., Carbó, J. M., Matalonga, J., et al. (2013). Reciprocal negative cross-talk between liver X receptors (LXRs) and STAT1: effects on IFN- $\gamma$-induced inflammatory responses and LXRdependent gene expression. J. Immun. 190, 6520-6532. doi: 10.4049/ jimmunol.1201393

Perucha, E., Melchiotti, R., Bibby, J. A., Wu, W., Frederiksen, K. S., Roberts, C. A., et al. (2019). The cholesterol biosynthesis pathway regulates IL-10 expression in human Th1 cells. Nat. Commun. 10:498. doi: 10.1038/s41467-019-08332-9

Pineda Torra, I., Claudel, T., Duval, C., Kosykh, V., Fruchart, J.-C., and Staels, B. (2003). Bile acids induce the expression of the human peroxisome proliferatoractivated receptor alpha gene via activation of the farnesoid $\mathrm{X}$ receptor. Mol. Endocrinol. 17, 259-272. doi: 10.1210/me.2002-0120

Poh, M. K., Shui, G., Xie, X., Shi, P.-Y., Wenk, M. R., and Gu, F. (2012). U18666A, an intra-cellular cholesterol transport inhibitor, inhibits dengue virus entry and replication. Antivir. Res. 93, 191-198. doi: 10.1016/j. antiviral.2011.11.014

Qiao, L., Wu, Q., Lu, X., Zhou, Y., Fernández-Alvarez, A., Ye, L., et al. (2013). SREBP-1a activation by $\mathrm{HBx}$ and the effect on hepatitis $\mathrm{B}$ virus enhancer II/core promoter. Biochem. Biophys. Res. Commun. 432, 643-649. doi: 10.1016/j. bbrc.2013.02.030

Raghu, H., Sharma-Walia, N., Veettil, M. V., Sadagopan, S., Caballero, A., Sivakumar, R., et al. (2007). Lipid rafts of primary endothelial cells are essential for Kaposi's sarcoma-associated herpesvirus/human herpesvirus 8-induced phosphatidylinositol 3-kinase and RhoA-GTPases critical for microtubule dynamics and nuclear delivery of viral DNA but dispensable for binding and entry. J. Virol. 81, 7941-7959. doi: 10.1128/JVI. 02848-06

Rehwinkel, J., and Gack, M. U. (2020). RIG-I-like receptors: their regulation and roles in RNA sensing. Nat. Rev. Immunol. 20, 537-551. doi: 10.1038/ s41577-020-0288-3

Renga, B., Migliorati, M., Mencarelli, A., and Fiorucci, S. (2009). Reciprocal regulation of the bile acid-activated receptor FXR and the interferon-gammaSTAT-1 pathway in macrophages. Biochim. Biophys. Acta 1792, 564-573. doi: 10.1016/j.bbadis.2009.04.004

Ridsdale, A., Denis, M., Gougeon, P.-Y., Ngsee, J. K., Presley, J. F., and Zha, X. (2006). Cholesterol is required for efficient endoplasmic reticulum-to-Golgi transport of secretory membrane proteins. Mol. Biol. Cell 17, 1593-1605. doi: $10.1091 / \mathrm{mbc}$.e05-02-0100

Ripa, I., Andreu, S., López-Guerrero, J. A., and Bello-Morales, R. (2021). Membrane rafts: portals for viral entry. Front. Microbiol. 12:631274. doi: 10.3389/fmicb.2021.631274

Robertson, K. A., and Ghazal, P. (2016). Interferon control of the sterol metabolic network: bidirectional molecular circuitry-mediating host protection. Front. Immunol. 7:634. doi: 10.3389/fimmu.2016.00634

Robinet, P., Fradagrada, A., Monier, M.-N., Marchetti, M., Cogny, A., Moatti, N., et al. (2006). Dynamin is involved in endolysosomal cholesterol delivery to the endoplasmic reticulum: role in cholesterol homeostasis. Traffic 7, 811-823. doi: 10.1111/j.1600-0854.2006.00435.x

Rocha, N., Kuijl, C., van der Kant, R., Janssen, L., Houben, D., Janssen, H., et al. (2009). Cholesterol sensor ORP1L contacts the ER protein VAP to control Rab7-RILP-p150 glued and late endosome positioning. J. Cell Biol. 185, 1209-1225. doi: 10.1083/jcb.200811005

Rodal, S. K., Skretting, G., Garred, O., Vilhardt, F., van Deurs, B., and Sandvig, K. (1999). Extraction of cholesterol with methyl-beta-cyclodextrin perturbs formation of clathrin-coated endocytic vesicles. Mol. Biol. Cell 10, 961-974. doi: $10.1091 / \mathrm{mbc} .10 .4 .961$

Sabino, C., Basic, M., Bender, D., Elgner, F., Himmelsbach, K., and Hildt, E. (2019). Bafilomycin A1 and U18666A efficiently impair ZIKV infection. Viruses 11:524. doi: 10.3390/v11060524

Samsa, M. M., Mondotte, J. A., Iglesias, N. G., Assunção-Miranda, I., Barbosa-Lima, G., Da Poian, A. T., et al. (2009). Dengue virus capsid protein usurps lipid droplets for viral particle formation. PLoS Pathog. 5:e1000632. doi: 10.1371/journal.ppat.1000632

Sanchez, V., and Dong, J. J. (2010). Alteration of lipid metabolism in cells infected with human cytomegalovirus. Virology 404, 71-77. doi: 10.1016/j. virol.2010.04.026

Scholtes, C., Diaz, O., Icard, V., Kaul, A., Bartenschlager, R., Lotteau, V., et al. (2008). Enhancement of genotype 1 hepatitis $C$ virus replication by bile acids through FXR. J. Hepatol. 48, 192-199. doi: 10.1016/j.jhep.2007.09.015

Schroeder, C. (2010). Cholesterol-binding viral proteins in virus entry and morphogenesis. Subcell. Biochem. 51, 77-108. doi: 10.1007/978-90-481-8622-8_3

Seol, W., Choi, H. S., and Moore, D. D. (1995). Isolation of proteins that interact specifically with the retinoid $\mathrm{X}$ receptor: two novel orphan receptors. Mol. Endocrinol. 9, 72-85. doi: 10.1210/mend.9.1.7760852

Sheng, X.-X., Sun, Y.-J., Zhan, Y., Qu, Y.-R., Wang, H.-X., Luo, M., et al. (2016). The LXR ligand GW3965 inhibits Newcastle disease virus infection by affecting cholesterol homeostasis. Arch. Virol. 161, 2491-2501. doi: 10.1007/ s00705-016-2950-4

Shirasaki, T., Honda, M., Shimakami, T., Horii, R., Yamashita, T., Sakai, Y., et al. (2013). MicroRNA-27a regulates lipid metabolism and inhibits hepatitis C virus replication in human hepatoma cells. J. Virol. 87, 5270-5286. doi: 10.1128/JVI.03022-12

Sleijfer, S., Bannink, M., van Gool, A. R., Kruit, W. H. J., and Stoter, G. (2005). Side effects of interferon-alpha therapy. Pharm. World Sci. 27, 423-431. doi: 10.1007/s11096-005-1319-7

Sobo, K., Chevallier, J., Parton, R. G., Gruenberg, J., and van der Goot, F. G. (2007). Diversity of raft-like domains in late endosomes. PLoS One 2:e391. doi: 10.1371/journal.pone.0000391

Soto-Acosta, R., Mosso, C., Cervantes-Salazar, M., Puerta-Guardo, H., Medina, F., Favari, L., et al. (2013). The increase in cholesterol levels at early stages after dengue virus infection correlates with an augment in LDL particle uptake and HMG-CoA reductase activity. Virology 442, 132-147. doi: 10.1016/j. virol.2013.04.003

Sousa, I. P., Carvalho, C. A. M., and Gomes, A. M. O. (2020). Current understanding of the role of cholesterol in the life cycle of alphaviruses. Viruses 13:35. doi: 10.3390/v13010035

Spann, N. J., Garmire, L. X., McDonald, J. G., Myers, D. S., Milne, S. B., Shibata, N., et al. (2012). Regulated accumulation of desmosterol integrates macrophage lipid metabolism and inflammatory responses. Cell 151, 138-152. doi: 10.1016/j.cell.2012.06.054

Stoeck, I. K., Lee, J.-Y., Tabata, K., Romero-Brey, I., Paul, D., Schult, P., et al. (2018). Hepatitis C virus replication depends on endosomal cholesterol homeostasis. J. Virol. 92, e01196-e01117. doi: 10.1128/JVI.01196-17

Stoorvogel, W., Strous, G. J., Geuze, H. J., Oorschot, V., and Schwartzt, A. L. (1991). Late endosomes derive from early endosomes by maturation. Cell 65, 417-427. doi: 10.1016/0092-8674(91)90459-C

Stratton, B. S., Warner, J. M., Wu, Z., Nikolaus, J., Wei, G., Wagnon, E., et al. (2016). Cholesterol increases the openness of SNARE-mediated flickering fusion pores. Biophys. J. 110, 1538-1550. doi: 10.1016/j.bpj.2016.02.019

Sun, L.-P., Seemann, J., Goldstein, J. L., and Brown, M. S. (2007). Sterolregulated transport of SREBPs from endoplasmic reticulum to Golgi: Insig renders sorting signal in Scap inaccessible to COPII proteins. Proc. Natl. Acad. Sci. U. S. A. 104, 6519-6526. doi: 10.1073/pnas.0700907104

Sundquist, W. I., and Kräusslich, H.-G. (2012). HIV-1 assembly, budding, and maturation. Cold Spring Harb. Perspect. Med. 2:a006924. doi: 10.1101/ cshperspect.a006924

Szanto, A., Benko, S., Szatmari, I., Balint, B. L., Furtos, I., Rühl, R., et al. (2004). Transcriptional regulation of human CYP27 integrates retinoid, peroxisome proliferator-activated receptor, and liver $\mathrm{X}$ receptor signaling in 
macrophages. Mol. Cell. Biol. 24, 8154-8166. doi: 10.1128/ MCB.24.18.8154-8166.2004

Tang, Y., Leao, I. C., Coleman, E. M., Broughton, R. S., and Hildreth, J. E. K. (2009). Deficiency of niemann-pick type C-1 protein impairs release of human immunodeficiency virus type 1 and results in gag accumulation in late endosomal/lysosomal compartments. J. Virol. 83, 7982-7995. doi: 10.1128/ JVI.00259-09

Thakur, S., Relich, P. K., Sorokina, E. M., Gyparaki, M. T., and Lakadamyali, M. (2020). ORP1L regulates dynein clustering on endolysosmal membranes in response to cholesterol levels. bioRxiv [Preprint]. doi: 10.1101/2020.08.28.273037

UHLER, M., and GARD, S. (1954). Lipid content of standard and incomplete influenza A virus. Nature 173, 1041-1042. doi: 10.1038/1731041a0

Venardos, N., Deng, X.-S., Yao, Q., Weyant, M. J., Reece, T. B., Meng, X., et al. (2018). Simvastatin reduces the TLR4-induced inflammatory response in human aortic valve interstitial cells. J. Surg. Res. 230, 101-109. doi: 10.1016/j.jss.2018.04.054

Wang, Y., Hao, J., Liu, X., Wang, H., Zeng, X., Yang, J., et al. (2016). The mechanism of apoliprotein A1 down-regulated by hepatitis B virus. Lipids Health Dis. 15:64. doi: 10.1186/s12944-016-0232-5

Wang, S., Li, W., Hui, H., Tiwari, S. K., Zhang, Q., Croker, B. A., et al. (2020). Cholesterol 25-hydroxylase inhibits SARS-CoV-2 and other coronaviruses by depleting membrane cholesterol. EMBO J. 39:e106057. doi: 10.15252/ embj.2020106057

Wang, Q., Ma, X., Chen, Y., Zhang, L., Jiang, M., Li, X., et al. (2014). Identification of interferon $-\gamma$ as a new molecular target of liver $\mathrm{X}$ receptor. Biochem. J. 459, 345-354. doi: 10.1042/BJ20131442

Wang, H., Perry, J., Lauring, A., Neddermann, P., de Francesco, R., and Tai, A. (2014). Oxysterol-binding protein is a phosphatidylinositol 4-kinase effector required for $\mathrm{HCV}$ replication membrane integrity and cholesterol trafficking. Gastroenterology 146, 1373.e1-11-1385.e1-11. doi: 10.1053/j.gastro.2014.02.002

Wang, X., Sato, R., Brown, M. S., Hua, X., and Goldstein, J. L. (1994). SREBP-1, a membrane-bound transcription factor released by sterol-regulated proteolysis. Cell 77, 53-62. doi: 10.1016/0092-8674(94)90234-8

Wang, Y., Thiele, C., and Huttner, W. B. (2000). Cholesterol is required for the formation of regulated and constitutive secretory vesicles from the transGolgi network. Traffic 1, 952-962. doi: 10.1034/j.1600-0854.2000.011205.x

Wang, F., Xia, W., Liu, F., Li, J., Wang, G., and Gu, J. (2012). Interferon regulator factor 1/retinoic inducible gene I (IRF1/RIG-I) axis mediates 25-hydroxycholesterol-induced interleukin-8 production in atherosclerosis. Cardiovasc. Res. 93, 190-199. doi: 10.1093/cvr/cvr260

Wang, L., Xie, W., Zhang, L., Li, D., Yu, H., Xiong, J., et al. (2018). CVB3 nonstructural 2A protein modulates SREBP1a signaling via the MEK/ERK pathway. J. Virol. 92, e01060-e01018. doi: 10.1128/JVI.01060-18

Waris, G., Felmlee, D. J., Negro, F., and Siddiqui, A. (2007). Hepatitis C virus induces proteolytic cleavage of sterol regulatory element binding proteins and stimulates their phosphorylation via oxidative stress. J. Virol. 81, 8122-8130. doi: 10.1128/JVI.00125-07

Watari, H., Blanchette-Mackie, E. J., Dwyer, N. K., Glick, J. M., Patel, S., Neufeld, E. B., et al. (1999). Niemann-pick C1 protein: obligatory roles for $\mathrm{N}$-terminal domains and lysosomal targeting in cholesterol mobilization. Proc. Natl. Acad. Sci. U. S. A. 96, 805-810. doi: 10.1073/pnas.96.3.805

Westerterp, M., Fotakis, P., Ouimet, M., Bochem, A. E., Zhang, H., Molusky, M. M., et al. (2018). Cholesterol efflux pathways suppress Inflammasome activation, NETosis, and Atherogenesis. Circulation 138, 898-912. doi: 10.1161/ CIRCULATIONAHA.117.032636

Wilhelm, L. P., Wendling, C., Védie, B., Kobayashi, T., Chenard, M.-P., Tomasetto, C., et al. (2017). STARD3 mediates endoplasmic reticulum-to-endosome cholesterol transport at membrane contact sites. EMBO J. 36, 1412-1433. doi: 10.15252/ embj.201695917

Willard, K. A., Elling, C. L., Stice, S. L., and Brindley, M. A. (2018). The oxysterol 7-Ketocholesterol reduces Zika virus titers in Vero cells and human neurons. Viruses 11:20. doi: 10.3390/v11010020

Willinger, T. (2019). Oxysterols in intestinal immunity and inflammation. J. Intern. Med. 285, 367-380. doi: 10.1111/joim. 12855

Xie, S., Bahl, K., Reinecke, J. B., Hammond, G. R. V., Naslavsky, N., and Caplan, S. (2016). The endocytic recycling compartment maintains cargo segregation acquired upon exit from the sorting endosome. Mol. Biol. Cell 27, 108-126. doi: 10.1091/mbc.E15-07-0514
Yandrapalli, N., Lubart, Q., Tanwar, H. S., Picart, C., Mak, J., Muriaux, D., et al. (2016). Self assembly of HIV-1 gag protein on lipid membranes generates PI(4,5)P2/cholesterol nanoclusters. Sci. Rep. 6:39332. doi: 10.1038/ srep39332

Yang, T., Espenshade, P. J., Wright, M. E., Yabe, D., Gong, Y., Aebersold, R., et al. (2002). Crucial step in cholesterol homeostasis: sterols promote binding of SCAP to INSIG-1, a membrane protein that facilitates retention of SREBPs in ER. Cell 110, 489-500. doi: 10.1016/S0092-8674(02)00872-3

Yang, Y., Zhu, Z., Fan, L., Ye, S., Lou, K., Hua, X., et al. (2020). Low serum level of apolipoprotein A1 is an indicator of severity in patients with coronavirus disease 2019 [Preprint].

Yokoyama, C., Wang, X., Briggs, M. R., Admon, A., Wu, J., Hua, X., et al. (1993). SREBP-1, a basic-helix-loop-helix-leucine zipper protein that controls transcription of the low density lipoprotein receptor gene. Cell 75, 187-197. doi: 10.1016/S0092-8674(05)80095-9

Yu, C.-Y., Liang, J.-J., Li, J.-K., Lee, Y.-L., Chang, B.-L., Su, C.-I., et al. (2015). Dengue virus impairs mitochondrial fusion by cleaving Mitofusins. PLoS Pathog. 11:e1005350. doi: 10.1371/journal.ppat.1005350

Yu, Y., Maguire, T. G., and Alwine, J. C. (2012). Human cytomegalovirus infection induces adipocyte-like lipogenesis through activation of sterol regulatory element binding protein 1. J. Virol. 86, 2942-2949. doi: 10.1128/ JVI.06467-11

Yuan, S., Chu, H., Chan, J. F.-W., Ye, Z.-W., Wen, L., Yan, B., et al. (2019). SREBP-dependent lipidomic reprogramming as a broad-spectrum antiviral target. Nat. Commun. 10:120. doi: 10.1038/s41467-018-08015-x

Zamorano Cuervo, N., Osseman, Q., and Grandvaux, N. (2018). Virus infection triggers MAVS polymers of distinct molecular weight. Viruses 10:56. doi: $10.3390 / \mathrm{v} 10020056$

Zhang, L., Ju, Y., Chen, S., and Ren, L. (2021). Recent Progress on exosomes in RNA virus infection. Viruses 13:256. doi: 10.3390/v13020256

Zhao, J., Chen, J., Li, M., Chen, M., and Sun, C. (2020). Multifaceted functions of $\mathrm{CH} 25 \mathrm{H}$ and $25 \mathrm{HC}$ to modulate the lipid metabolism, immune responses, and broadly antiviral activities. Viruses 12:727. doi: 10.3390/v12070727

Zhao, G.-J., Yin, K., Fu, Y.-C., and Tang, C.-K. (2012). The interaction of ApoA-I and ABCA1 triggers signal transduction pathways to mediate efflux of cellular lipids. Mol. Med. 18, 149-158. doi: 10.2119/molmed.2011. 00183

Zheng, D., Liwinski, T., and Elinav, E. (2020). Inflammasome activation and regulation: toward a better understanding of complex mechanisms. Cell Discov. 6:36. doi: 10.1038/s41421-020-0167-x

Zhu, X., Lee, J.-Y., Timmins, J. M., Brown, J. M., Boudyguina, E., Mulya, A., et al. (2008). Increased cellular free cholesterol in macrophage-specific Abcal knock-out mice enhances pro-inflammatory response of macrophages. $J$. Biol. Chem. 283, 22930-22941. doi: 10.1074/jbc.M801408200

Zhu, X., Owen, J. S., Wilson, M. D., Li, H., Griffiths, G. L., Thomas, M. J., et al. (2010). Macrophage ABCA1 reduces MyD88-dependent toll-like receptor trafficking to lipid rafts by reduction of lipid raft cholesterol. J. Lipid Res. 51, 3196-3206. doi: 10.1194/jlr.M006486

Zu, S., Deng, Y.-Q., Zhou, C., Li, J., Li, L., Chen, Q., et al. (2020). 25-hydroxycholesterol is a potent SARS-CoV-2 inhibitor. Cell Res. 30, 1043-1045. doi: 10.1038/s41422-020-00398-1

Conflict of Interest: The authors declare that the research was conducted in the absence of any commercial or financial relationships that could be construed as a potential conflict of interest.

Publisher's Note: All claims expressed in this article are solely those of the authors and do not necessarily represent those of their affiliated organizations, or those of the publisher, the editors and the reviewers. Any product that may be evaluated in this article, or claim that may be made by its manufacturer, is not guaranteed or endorsed by the publisher.

Copyright $\odot 2021$ Glitscher and Hildt. This is an open-access article distributed under the terms of the Creative Commons Attribution License (CC BY). The use, distribution or reproduction in other forums is permitted, provided the original author(s) and the copyright owner(s) are credited and that the original publication in this journal is cited, in accordance with accepted academic practice. No use, distribution or reproduction is permitted which does not comply with these terms. 